\title{
Performance of CMOS Schmitt Trigger
}

\author{
R. Sapawi, R.L.S Chee, S.K Sahari, N. Julai \\ Department of Electronics, Faculty of Engineering, \\ Universiti Malaysia Sarawak, 94300 Kota Samarahan, Sarawak. \\ Tel: 082-583289 \\ Email: srohana@feng.unimas.my
}

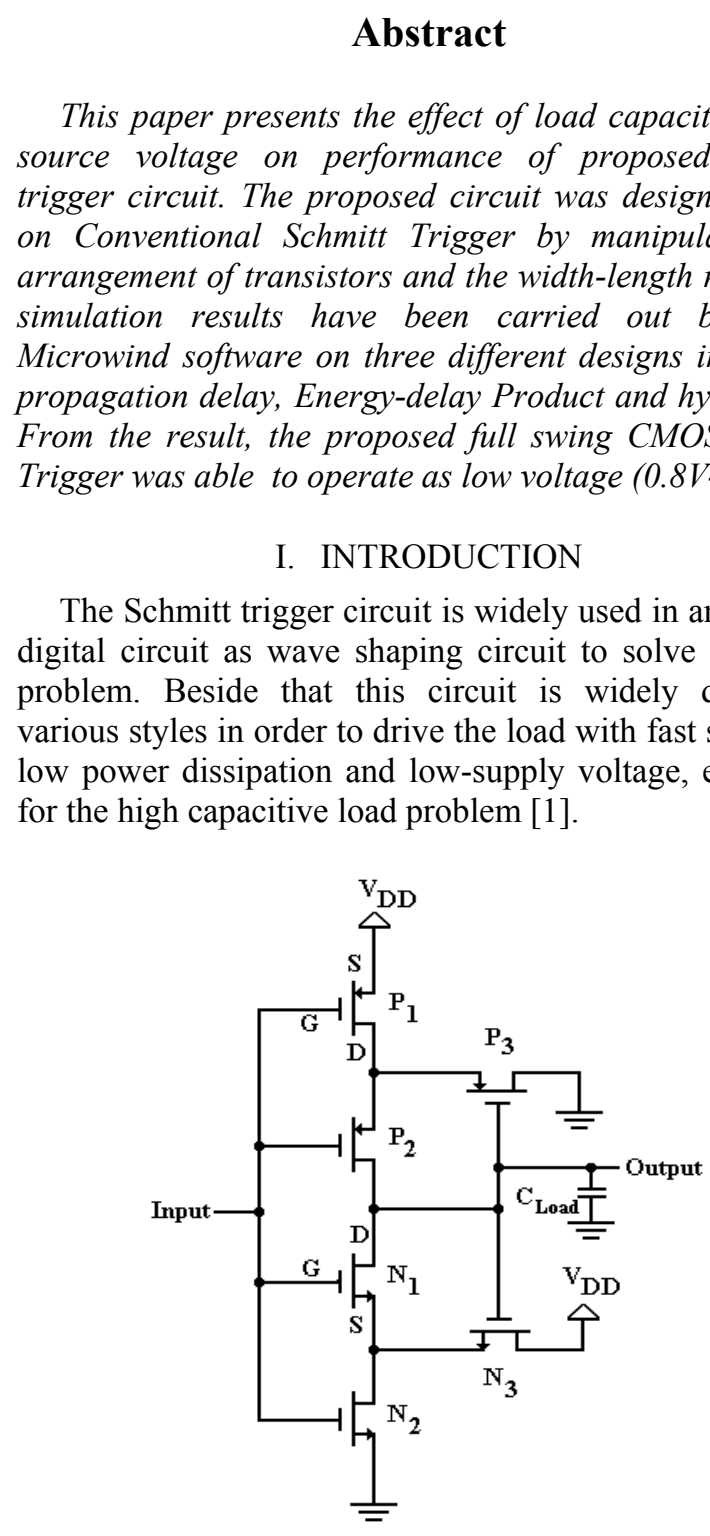

Figure 1. The Conventional Schmitt Trigger
Conventional Schmitt Trigger is shown in Figure 1 and the detail design is presented in [2] where the switching thresholds are dependent on the ratio of NMOS and PMOS. However, this circuit will exhibit racing phenomena after the transition starts. Therefore in this paper, we proposed CMOS Schmitt Trigger circuit which is capable to operate in low voltages $(0.8 \mathrm{~V}$ $1.5 \mathrm{~V})$ at high capacitance, less propagation delay and stable hysteresis width.

\section{CIRCUIT DESCRIPTION}

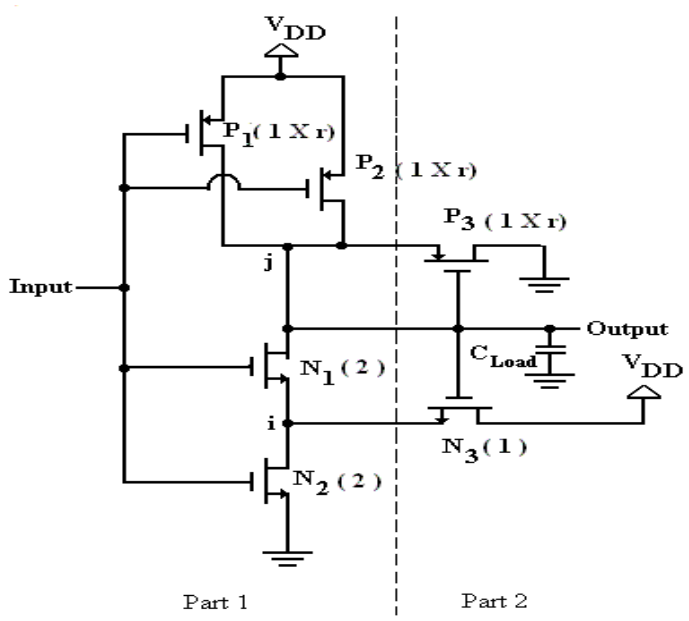

Figure 2. The Proposed Schmitt Trigger

The proposed Schmitt Trigger [3] is shown in Figure 2 and is categorized into two parts which is Part 1 and Part 2. Similarly to Conventional Schmitt Trigger, the proposed circuit is formed by a combination of two subcircuits, $\mathrm{P}$ sub-circuit (which consist of $\mathrm{P}_{1}, \mathrm{P}_{2}$ and $\mathrm{P}_{3}$ ) and $\mathrm{N}$ sub-circuit (which consist of $\mathrm{N}_{1}$, $\mathrm{N}_{2}$ and $\mathrm{N}_{3}$ ). There is no direct connection between the source voltage and ground as $\mathrm{P}$ sub-circuit is connected to the path between the source voltage and output while the $\mathrm{N}$ sub- 